\title{
Straight blades improve visualization of the larynx while curved blades increase ease of intubation: a comparison of the Macintosh, Miller, McCoy, Belscope and Lee-Fiberview blades
}

\section{[Les lames droites améliorent la visualisation du larynx tandis que les lames courbes facilitent}

l'intubation : une comparaison des lames Macintosh, Miller, McCoy, Belscope et Lee-Fiberview]

Jose J. Arino MD PhD, Jose M. Velasco MD, Carmen Gasco MD PhD, Francisco Lopez-Timoneda MD PhD

Purpose: To compare the Macintosh (M), McCoy (MC), Miller (MIL), Belscope (BP) and Lee-Fiberview (LF) laryngoscopes with respect to the grade of laryngeal visualization and the difficulty of intubation.

Methods: We included 500 patients scheduled to undergo elective surgery and who required tracheal intubation. Patients were randomly assigned to five groups of 100 patients each. Anesthesia was induced intravenously using $\mathrm{I}-3 \mathrm{mg} \cdot \mathrm{kg}^{-1}$ of propofol, fentanyl $1.5 \mu \mathrm{g} \cdot \mathrm{kg}^{-1}$ and atracurium $0.5 \mathrm{mg} \cdot \mathrm{kg}^{-1}$ or suxamethonium । $\mathrm{mg} \cdot \mathrm{kg}^{-1}$. The laryngeal view was classified according to Cormack and Lehane. The degree of difficulty with intubation was rated as: Grade I, intubation easy; Grade 2, intubation requiring an increased anterior lifting force and assistance to pull the right corner of the mouth upwards to increase space; Grade 3, intubation requiring multiple attempts and a curved stylet; Grade 4, failure to intubate with the assigned laryngoscope. Data were examined using analysis of variance, $\chi^{2}$ or Fisher test, Student's t test and odds ratio. $P<0.05$ was considered statistically significant.

Results: Laryngoscopic views obtained with the BP and MIL laryngoscopes were similar, and better than with the other types of laryngoscopes $(P<0.00 \mathrm{I})$. The levering tip of the $\mathrm{MC}$ blade $(P=$ $0.02)$ and the fibreoptic device of the LF $(P<0.001)$ significantly improved the laryngoscopic view.

Regarding the degree of difficulty with intubation, the best results were obtained with the $M C$ and $M$ blades $(P<0.00 I)$.

Conclusion: Laryngoscopy was better with straight blades but curved blades provided better intubating conditions.
Objectif: Comparer les laryngoscopes Macintosh (M), McCoy (MC), Miller (MIL), Belscope (BP) et Lee-Fiberview (LF) quant au degré de visualisation du larynx et à la difficulté d'intubation.

Méthode : L'étude a porté sur 500 patients devant subir une intervention chirurgicale réglée nécessitant une intubation endotrachéale. Les patients ont été répartis en cinq groupes de 100 patients chacun. L'anesthésie a été induite par l'administration intraveineuse de I-3 $\mathrm{mg} \cdot \mathrm{kg}^{-1}$ de propofol, $1,5 \mu \mathrm{g} \cdot \mathrm{kg}^{-1}$ de fentanyl et $0,5 \mathrm{mg} \cdot \mathrm{kg}^{-1}$ d'a- $^{\prime}$ tracurium ou I $\mathrm{mg} \cdot \mathrm{kg}^{-1}$ de suxaméthonium. La visualisation du larynx a été cotée selon Cormack et Lehane. Le degré de difficulté d'intubation a été noté comme suit : Classe I, intubation facile ; Classe 2, intubation nécessitant de soulever l'appareil vers l'avant avec une force croissante et une assistance pour pousser le coin droit de la bouche vers le haut pour accentuer l'ouverture ; Classe 3, intubation nécessitant plus d'un essai et un stylet courbe ; Classe 4, échec de l'intubation avec le laryngoscope testé. Les données ont été étudiées avec une analyse de variance, le test du $\chi^{2}$ ou le test de Fisher, le test de Student et le risque relatif. $P<0,05$ a été considéré significatif.

Résultats : La visualisation laryngoscopique a été similaire avec le BP et le MIL, et meilleure qu'avec les autres appareils ( $P<0,00$ I). La pointe levier de la lame $M C(P=0,02)$ et la composante fibroscopique du LF $(P<0,001)$ ont significativement amélioré la visualisation du larynx. Relativement au degré de difficulté d'intubation, les meilleurs résultats ont été obtenus avec les lames $M C$ et $M(P<$ 0,001 )

Conclusion : La laryngoscopie a été meilleure avec les lames droites, mais les lames courbes ont facilité les conditions d'intubation.

From the Department of Anesthesia, Hospital Clinico San Carlos, Madrid, Spain.

Address correspondence to: Dr. Jose J. Arino, Department of Anesthesia, Hospital Clinico San Carlos, C/ Prof. Martin Lagos s/n,

28040 Madrid, Spain. Phone: 34-913303040; Fax: 34-913303039; E-mail: jarinoirujo@yahoo.es

Accepted for publication September 24, 2002.

Revision accepted February 12, 2003. 


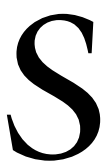

INCE the advent of tracheal intubation in anesthesia, many descriptions of laryngoscope designs have been published.

The Miller (MIL) and the Macintosh (M) laryngoscopes are used by most anesthesiologists for laryngoscopy and tracheal intubation.

The McCoy blade (MC; Penlon Ltd., Abingdon, UK; Figure 1 ) is a modification of the standard $M$ blade. ${ }^{1}$ The tip of the MC blade is hinged and when the MC blade is inserted into the vallecula, the tip acts on the hyoepiglotic ligament and lifts the epiglottis out of view to expose more of the glottis by compression of a lever attached to the proximal end of the blade.

The Belscope ${ }^{2}$ (BP; Avulunga Pty. Ltd., Murwillumbah, Australia; Figure 1) is essentially a straight blade bent at $45^{\circ}$ at its midpoint. The blade tip is beaded on its underside. As the angle of this blade can obscure the view of the larynx a prism made of transparent acrylic material allows to see around this angulation. The laryngoscope is used like a conventional straight-blade laryngoscope and, in the majority of cases, there is no need to use the prism.

The Lee-Fiberview Improved View Macintosh Fibreoptic Viewer Laryngoscope Blade (LF) (Anesthesia Medical Specialties, Santa Fe Springs, USA; Figure 1 ) is a modification of the standard M blade. The low profile improves the direct view of the larynx. This laryngoscope is used like a conventional straightbladed laryngoscope. The incorporation of a fibreoptic visual device (FVD) with a focusable scope attached to the proximal end of the blade provides a view of the larynx when direct sight is obstructed and makes it possible to see the tube slip between the vocal cords.

The aim of our study was to compare these devices with respect to laryngoscopic view and ease of intubation.

\section{Methods}

After obtaining local Ethical Committee approval and informed patient consent we included 500 patients scheduled to undergo elective surgery and who required tracheal intubation. Patients were excluded if they required rapid sequence induction and/or had a history of difficult tracheal intubation.

In this study a Classical M \#4 $(15 \mathrm{~cm})$, a $\mathrm{MC} \mathrm{\# 4}$ $(15 \mathrm{~cm})$, a MIL \#3 $(18.5 \mathrm{~cm})$, a BP $(16.5 \mathrm{~cm})$ and a LF blade \#4 $(16 \mathrm{~cm})$ were used.

Patients were randomly assigned to five groups of 100 patients each using random systematic assignment. Monitoring in the operating room included pulse oxymetry, electrocardiograph, capnography and automated non-invasive blood pressure measurement. Anesthesia was induced intravenously using 1-3 $\mathrm{mg} \cdot \mathrm{kg}^{-1}$ of propofol, fentanyl $1.5 \mu \mathrm{g} \cdot \mathrm{kg}^{-1}$ and atracurium $0.5 \mathrm{mg} \cdot \mathrm{kg}^{-1}$ or suxamethonium $\mathrm{l} \mathrm{mg} \cdot \mathrm{kg}^{-1}$. A doughnut-shaped pillow and a hard sponge square pillow, totaling about $7 \mathrm{~cm}$ in height, were placed under the head of each patient.

We used an integration of three predictive tests to score and grade the difficulty of intubation: ${ }^{3}$

\section{1) Mallampati's test $t^{4}$}

Measures the relative tongue/pharyngeal size. The observer classifies the airway according to the pharyngeal structures seen: Grade 1 = soft palate, fauces, uvula, anterior and posterior tonsillar pillars ( 1 point); Grade 2 = soft palate, fauces, uvula ( 2 points); Grade $3=$ soft palate, base of uvula ( 3 points); Grade $4=$ soft palate not visible at all ( 4 points).

\section{2) Atlanto-occipital joint extension ${ }^{5}$ (AOJE)}

When the AOJ is extended, the angle between the erect and extended planes of the occlusal surface of the upper teeth quantitates the degree of AOJE: Grade $\mathrm{l}=\mathrm{AOJE} \geq 35^{\circ}$ ( $\mathrm{l}$ point); Grade $2=\mathrm{AOJE} \geq$ $22^{\circ}$ and $<35^{\circ}\left(2\right.$ points); Grade $3=\mathrm{AOJE} \geq 13^{\circ}$ and $<22^{\circ}$ ( 3 points); Grade $4=\mathrm{AOJE}<13^{\circ}$ (4 points).

\section{3) Mandibular space}

Includes the thyromental distance (TMD) and the horizontal length of the mandible (LM): ${ }^{6}$ Grade $\mathrm{l}=\mathrm{TMD}$ $\geq 6 \mathrm{~cm}$ and $\mathrm{LM} \geq 9 \mathrm{~cm}$ (1 point); Grade $2=\mathrm{TMD} \geq 6$ $\mathrm{cm}$ and $\mathrm{LM}<9 \mathrm{~cm}(2$ points); Grade $3=\mathrm{TMD}<6 \mathrm{~cm}$ and $\mathrm{LM} \geq 9 \mathrm{~cm}$ ( 3 points); Grade $4=\mathrm{TMD}<6 \mathrm{~cm}$ and $\mathrm{LM}<9 \mathrm{~cm}$ (4 points).

Addition of the points generates a nominal score (intubation prediction score) and is classified as: Grade 1: easy intubation is predicted (3-4 points); Grade 2: moderately difficult intubation is predicted (5-8 points); Grade 3: difficult intubation is predicted (9-12 points).

Direct laryngoscopy was carried out under full muscle relaxation measured by a train-of-four monitoring. Only one anesthesiologist fully experienced in the use of the laryngoscopes was involved in the study. The laryngeal view was classified according to Cormack and Lehane ${ }^{7}$ as follows: Grade 1, full view of glottis; Grade 2, only posterior commisure visible; Grade 3, only epiglottis visible; Grade 4, no glottic structure visible.

In the MC group the laryngoscopic view was assessed with the blade tip in neutral and elevated positions when needed. In the BP group and in the LF group it was also assessed through the prism and the FVD respectively.

The degree of difficulty with intubation was rated as: Grade 1, intubation easy; Grade 2, intubation 
TABLE I Demographic data and difficulty of intubation prediction score

\begin{tabular}{|c|c|c|c|c|c|}
\hline & Macintosh & McCoy & Belscope & Miller & Lee \\
\hline $\begin{array}{l}\text { Sex* } \\
(\mathrm{m} / \mathrm{f})\end{array}$ & $42 / 58$ & $42 / 58$ & $49 / 51$ & $51 / 49$ & $56 / 44$ \\
\hline $\begin{array}{l}\text { Age } \\
(\mathrm{yr})\end{array}$ & $51.1(16.9)$ & $57.1(15.1)$ & $54.6(15.8)$ & $58.8(16.2)$ & $57.6(17.1)$ \\
\hline $\begin{array}{l}\text { Weight } \\
(\mathrm{kg})\end{array}$ & $68.9(17.4)$ & $69.5(14.8)$ & $74.2(21.6)$ & $73.6(23.5)$ & $71(18.8)$ \\
\hline $\begin{array}{l}\text { Height } \\
(\mathrm{cm})\end{array}$ & $165(7.4)$ & $162.9(7.2)$ & $164.3(8.1)$ & $163.1(8.5)$ & $164.3(18.8)$ \\
\hline $\begin{array}{l}\mathrm{BMI} \\
\left(\mathrm{kg} \cdot \mathrm{m}^{2}\right)\end{array}$ & $25.2(6.1)$ & $26.1(5.1)$ & $27.6(8.4)$ & $27.5(7.8)$ & $26.3(6.9)$ \\
\hline $\begin{array}{l}\text { IPS } \\
\text { (points) }\end{array}$ & $4.34(1.31)$ & $4.72(1.39)$ & $4.34(1.29)$ & $4.51(1.27)$ & $4.43(1.06)$ \\
\hline
\end{tabular}

${ }^{*}=$ Number of subjects. Values are mean $(\mathrm{SD}) . \mathrm{BMI}=$ body mass index; IPS = difficulty of intubation prediction score.

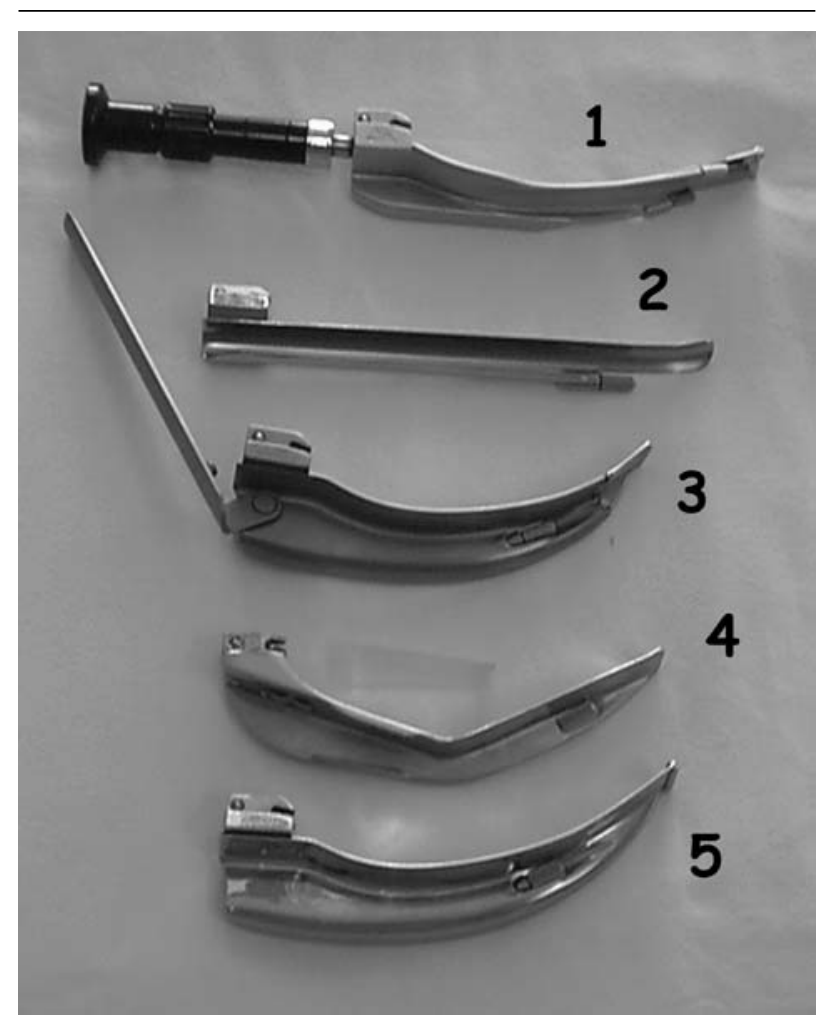

FIGURE 1 Laryngoscopes used in the study: 1) Lee-Fiberview; 2) Miller; 3) McCoy; 4) Belscope and prism; 5 ) Classical Macintosh.

requiring an increased anterior lifting force and assistance to pull the right corner of the mouth upwards to augment space; Grade 3, intubation requiring multiple attempts and a curved stylet; Grade 4, failure to intubate with the assigned laryngoscope.

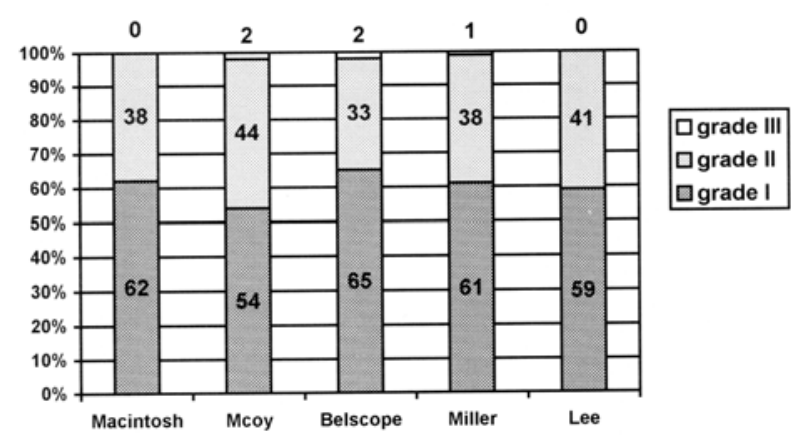

FIGURE 2 Difficulty of intubation prediction grades. Grade $1=$ easy intubation predicted ( $3-4$ points); Grade $2=$ moderately difficult intubation predicted (5-8 points); Grade $3=$ difficult intubation predicted (9-12 points). Data shown are percentages.

In the BP group the degree of difficulty of intubation was also assessed with the prism in 50 patients.

Data were examined using analysis of variance, $\chi^{2}$ or Fisher test, Student's t test and odds ratio. Data were expressed as percentages and mean (SD). $P<$ 0.05 was considered statistically significant.

\section{Results}

Demographic characteristics were similar in all groups except for age that differed between the M and MIL groups (Table I). The difficult intubation prediction scores and grades were similar in all groups (Table I and Figure 2).

Laryngoscopic views obtained with BP and MIL laryngoscopes were similar, and better than with the other types of laryngoscopes $(P<0.001)$. Laryngeal 
TABLE II Laryngeal views obtained with different blades

\begin{tabular}{|c|c|c|c|c|c|c|c|c|}
\hline $\begin{array}{l}\text { Cormack } \\
\text { grades }\end{array}$ & Macintosh & McCoy & $\begin{array}{l}\text { McCoy with } \\
\text { elevated tip }\end{array}$ & Belscope* & $\begin{array}{l}\text { Belscope } \\
\text { with prism }\end{array}$ & Miller* $\neq$ & Leet & $\begin{array}{l}\text { Lee with } \\
\text { FVD } \neq \mathbb{S}^{* *}\end{array}$ \\
\hline I & 72 & 69 & 87 & 98 & 92 & 96 & 79 & 92 \\
\hline II & 20 & 20 & 10 & 1 & 1 & 4 & 19 & 0 \\
\hline III & 7 & 11 & 3 & 0 & 1 & 0 & 2 & 0 \\
\hline IV & 1 & 0 & 0 & 1 & 0 & 0 & 0 & 0 \\
\hline No vision & 0 & 0 & 0 & 0 & 6 & 0 & 0 & 8 \\
\hline Total & 100 & 100 & 100 & 100 & 100 & 100 & 100 & 100 \\
\hline
\end{tabular}

Data shown are number of subjects. ${ }^{*} P<0.001$ vs other blades; ${ }^{*} P<0.001$ vs Macintosh; $\dagger P=0.02$ vs McCoy; $\ddagger P<0.01$ vs McCoy with elevated tip; $\mathbb{I} P=0.02$ vs McCoy; $\mathbb{S}<0.001$ vs Lee. No vision $=$ the view of the larynx was not obtained; FVD = fibreoptic visual device.

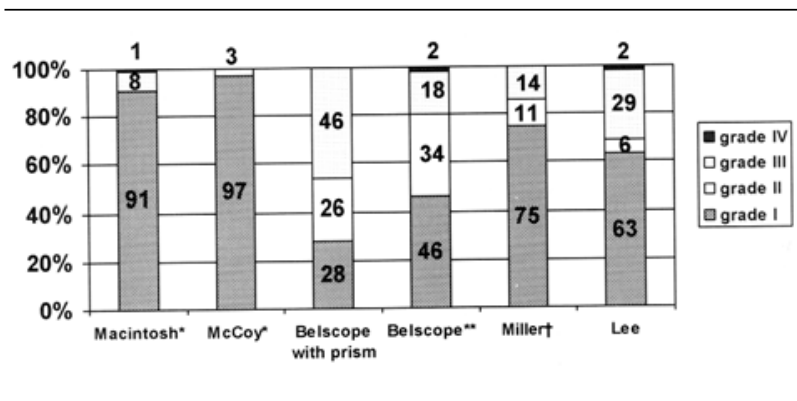

FIGURE 3 Grades of difficulty with intubation. Grade $1=$ intubation easy; Grade 2 = intubation requiring an increased anterior lifting force and assistance to pull the right corner of the mouth upwards to augment space; Grade 3 = intubation requiring multiple attempts and a curved stylet; Grade 4 = failure to intubate with the assigned laryngoscope. Data shown are percentages. ${ }^{*} P<$ 0.001 compared with other blades; ${ }^{*} P<0.05$ compared with Belscope with the prism (50 patients in each group); $† P<0.001$ compared with Lee or Belscope.

views obtained with the different devices are presented in detail in Table II. The levering tip of the MC blade $(P=0.02)$ and the FVD of the $\operatorname{LF}(P<0.001)$ significantly improved the laryngoscopic view.

Ease of intubation was highest with the $\mathrm{M}$ and $\mathrm{MC}$ blades $(P<0.001$; Figure 3$)$. Better results were obtained with the MIL blade than with the LF or BP blades $(P<0.001)$. The use of the prism with the BP blade significantly increased intubation difficulty $(46 \%$ vs $18 \%$ Grade $3 ; P<0.05)$.

In four patients (one in the $\mathrm{M}$ group, one in the $\mathrm{BP}$ group and two in the LF group) another laryngoscope blade or fibreoptic endoscopy was required for successful tracheal intubation.

\section{Discussion}

The results of this study confirm that laryngoscopy is better with straight blades but curved blades provide better intubating conditions.

The laryngoscope blades used in the clinical trial had a curved tip (MIL), were angulated (BP), curved throughout $(\mathrm{M})$, curved with low profile (LF) and curved with a hinged tip (MC). We used the larger M blade \#4 as theoretical and clinical observations have demonstrated its superiority to $M \# 3 .{ }^{8-10}$ The other blades were of similar sizes.

There were no significant differences in the difficulty of laryngoscopy and intubation prediction score between groups, so all groups were homogeneous. A similar intubation prediction score has been validated, ${ }^{3}$ showing better predictive capacity than each predictor taken individually ( $94 \%$ sensibility and a positive predictive value of $92 \%$ for Cormack I-II). ${ }^{3}$

When laryngoscopy is difficult with the curved blade, use of a straight type may help to achieve adequate laryngeal visualization. ${ }^{11}$ To overcome this prob$\mathrm{lem}$, the mid portion of the blade has been made more concave to reduce the crest-of-the- hill effect while the outer edge maintains the curved appearance (LF). With the laryngoscopes used like a conventional straightblade, the epiglottis is lifted directly. This avoids the situation where the hyoid bone cannot be displaced forward and the epiglottis continues to obstruct a view of the larynx. In addition, the back of the tongue is completely flattened to give a direct line of vision. While the view provided by the angulated laryngoscope (BP) is framed by the laryngoscope and the right side of the patient's mouth, the angle and the horizontal distal component (half) does not obscure the anterior part of the view as much as the curved blade does.

Some authors ${ }^{16}$ report that the MC and BP provide greater visibility than either the M or the MIL. Many 
studies report worse visibility with $M$ than with other blades. ${ }^{16-19}$

The MC blade was used in the neutral position when the view of the larynx was Grade 1. When needed, the tip of the MC blade was elevated and the view of the larynx was significantly improved by one or two grades in $80.6 \%$ of the patients and remained unchanged in $19.4 \%$ of the patients with Cormack II and III.

Chisholm et al. ${ }^{12}$ report that the MC blade is unlikely to improve a Cormack IV laryngoscopy. Tuckey et al. ${ }^{13}$ report impaired vision when the tip was levered in patients with Grades 1 and 2. We did not observe this variable effect on laryngeal view with the elevated tip. Possible explanations for these conflicting results may be that, in our study, the optimum depth of insertion was determined by the vallecula and the levering mechanism was gently activated until the best laryngeal view was obtained. Different authors have attempted to explain the effect on laryngeal view obtained with the MC laryngoscope. ${ }^{14,15}$

In 21 patients the FVD of the LF blade was needed and the view of the larynx was significantly improved by one grade in $85.7 \%$ of the patients. It remained unchanged in $14.3 \%$ of patients. In eight patients, the view of the larynx through the visor was not obtained because of secretions and the small size of the FVD.

In only two patients in the BP group was the prism required to improve the view. In one patient the prism improved visibility (Cormack IV to Cormack III). In six patients (Cormack I) the view of the larynx through the prism could not be obtained. Use of the prism with the BP blade significantly increased the difficulty of intubation as it interfered with passage of the endotracheal tube.

For intubation, best results were obtained with the curved MC and M blades $(P<0.001)$. Curved blades provide more room in the oropharynx to maneuver the endotracheal tube. The curved tip of the MIL blade helps to obtain better intubation conditions than other straight blades because it increases the exposure of the vocal cords and the room in which to maneuver the tracheal tube. ${ }^{9}$

In summary, a good laryngeal view with the intubating device did not equate with ease of intubation. Since the most important aspect of a laryngoscopic intubation is the correct placement of the endotracheal tube, and not the visualization of the larynx, based on our study of 500 patients, we recommend the use of a curved blade to improve intubating conditions.

\section{References}

1 McCoy EP, Mirakhur RK. The levering laryngoscope. Anaesthesia 1993; 48: 516-9.
2 Bellhouse CP. An angulated laryngoscope for routine and difficult tracheal intubation. Anesthesiology 1988; 69: 126-9.

3 Perucho A, Ariño JJ, Santé L, Yuste J, Timoneda FL. Recognition of the difficult airway. An integrated test. Br J Anaesth 1997; 78: 11 (abstract).

4 Mallampati SR. Clinical signs to predict difficult tracheal intubation (hypothesis) (Letter). Can Anaesth Soc J 1983; 30: 316-7.

5 Bellhouse CP, Doré C. Criteria for estimating likelihood of difficulty of endotracheal intubation with the

Macintosh laryngoscope. Anaesth Intensive Care 1988; 16: 329-37.

6 Benumof JL. Management of the difficult adult airway. With special emphasis on awake tracheal intubation. Anesthesiology 1991; 75: 1087-110.

7 Cormack RS, Lehane J. Difficult tracheal intubation in obstetrics. Anaesthesia 1984; 39: 1105-11.

8 Yardeni IZ, Gefen A, Smolyarenko V, Zeidel A, Beilin B. Design evaluation of commonly used rigid and levering laryngoscope blades. Acta Anaesthesiol Scand 2002; 46: 1003-9.

9 Marks RRD, Hancock R, Charters P. An analysis of laryngoscope blade shape and design: new criteria for laryngoscope evaluation. Can J Anaesth 1993; 40: 262-70.

10 Relle A. Laryngoscope design (Letter). Can J Anaesth 1994; 41: 162-3.

11 Benumof JL. Difficult laryngoscopy: obtaining the best view (Editorial). Can J Anaesth 1994; 41: 361-5.

12 Chisholm DG, Calder I. Experience with the McCoy laryngoscope in difficult laryngoscopy. Anaesthesia 1997; 52: 906-8.

13 Tuckey JP, Cook TM, Render CA. An evaluation of the levering laryngoscope. Anaesthesia 1996; 51: 71-3.

14 Levitan RM, Ochroch EA. Explaining the variable effect on laryngeal view obtained with the McCoy laryngoscope (Letter). Anaesthesia 1999; 54: 599-620.

15 Aoyama K, Nagaoka E, Takenaka I, Kadoya T. The McCoy laryngoscope expands the laryngeal aperture in patients with difficult intubation (Letter).

Anesthesiology 2000; 92: 1855-6.

16 Bito H, Nishiyama T, Higashizawa T, Sakai T, Konishi $A$. Determination of the distance between the upper incisors and the laryngoscope blade during laryngoscopy: comparisons of the McCoy, the Macintosh, the Miller, and the Belscope blades. Masui 1998; 47: 1257-61.

17 Watanabe S, Suga A, Asakura N, et al. Determination of the distance between the laryngoscope blade and the upper incisors during direct laryngoscopy: comparisons of a curved, an angulated straight, and the two straight blades. Anesth Analg 1994; 79: 638-41. 
18 Sakai T, Konishi A, Nishiyama T, Higashizawa T, Bito $H$. A comparison of the grade of laryngeal visualisation-the McCoy compared with the Macintosh and the Miller blade in adults. Masui 1998; 47: 998-1001.

19 Taguchi N, Watanabe S, Kumagai M, Takeshima R, Asakura N. Radiographic documentation of increased visibility of the larynx with a Belscope laryngoscope blade. Anesthesiology 1994; 81: 773-5. 